\title{
Vegetation Phenology Metrics Derived from Temporally Smoothed and Gap- filled MODIS Data
}

Bin Tan ${ }^{1,2}$, Jeff Morisette ${ }^{3}$, Robert Wolfe ${ }^{1}$, Wayne Esaias ${ }^{1}$, Feng Gao ${ }^{4}$, Greg Ederer $^{1,5}$, Joanne Nightingale ${ }^{1,5}$, Jamie. E. Nickeson ${ }^{1,5}$, Pete. Ma ${ }^{1,5}$ and Jeff Pedely ${ }^{1}$.

${ }^{1}$ Terrestrial Information Systems Branch (614.5)

NASA Goddard Space Flight Center, Greenbelt, MD, USA

${ }^{2}$ ERT Inc., ${ }^{3}$ USGS, ${ }^{4}$ USDA, ${ }^{5}$ Sigma Space Inc. 


\section{Background}

Why the vegetation phenology is important:

- Reflect the dynamics of the Earth's climate and hydrologic regimes.

- Connect biosphere and atmosphere

- Large-scale vegetation phenology is useful for studies of seasonal and interannual variability in carbon exchange, vegetation-climate interactions and other ecology processes. 


\section{Background}

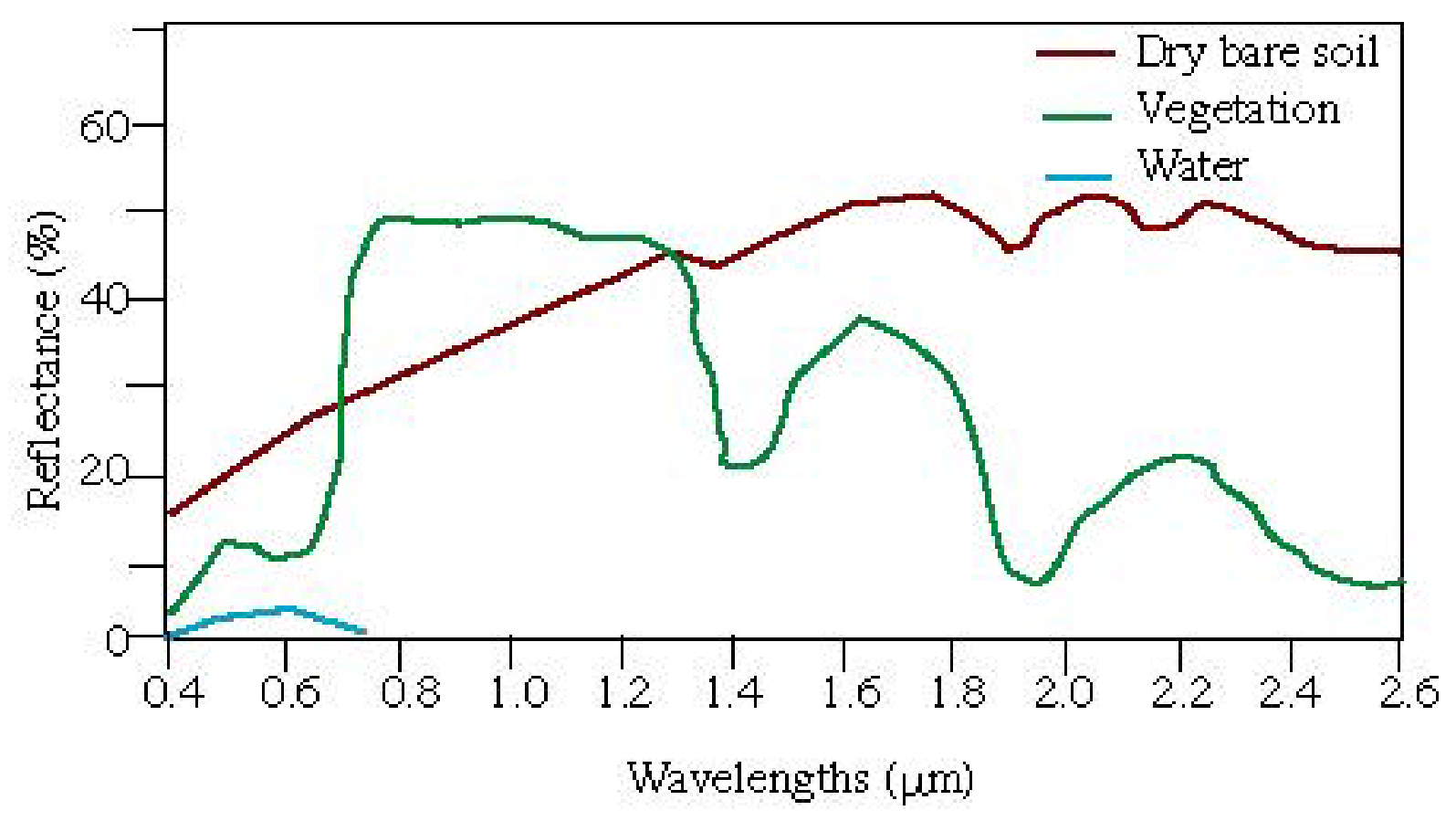

Typical spectral reflectance curves for vegetation, soil, and water. 


\section{Vegetation Index}

$$
N D V I=\frac{N I R-R E D}{N I R+R E D}
$$

$$
E V I=G \times \frac{(N I R-R E D)}{\left(N I R+C_{1} \times R E D-C_{2} \times B L U E+L\right)}
$$

For MODIS, $G=2.5, C_{1}=6, C_{2}=7.5$ and $L=1$ 


\section{Challenges in deriving phenology metrics from remote sensing data}

- The inherent noise due to variations in viewing geometry, and less than ideal atmospheric conditions, etc., reasons.

- Occasional missing data due to cloud cover and dead sensor, etc., unpredictable situations.

Solution:

Estimate phenology metrics from smoothed and gap-filled data sets. 


\section{Two Temporal Curve Fitting Cases}

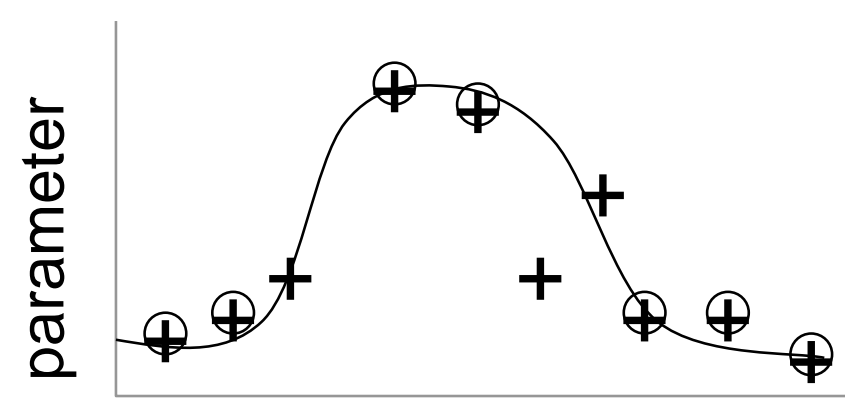

Case 1 - typical situation: enough high quality data to adequately fit curve to the retrievals

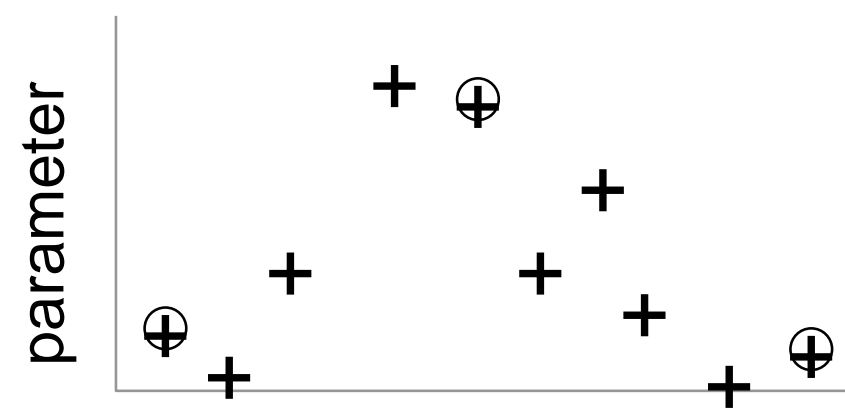

Case 2 - degenerate situation: not enough high quality pixels to adequately fit curve to the retrievals

time

+ Original time series

$\oplus$ High quality values

— Temporal curve fitting

F. Gao, J. T. Morisette, R. E. Wolfe, G. Ederer, J. Pedelty, E. Masuoka, R. Myneni, B. Tan and J. Nightingale, “An algorithm to produce temporally and spatially continuous MODIS-LAI time series,” IEEE Tran Geosci Remote Sens Letters, 5, 60-64, 2008. 


\section{Modified TIMESAT Parameters}

1. Beginning of season

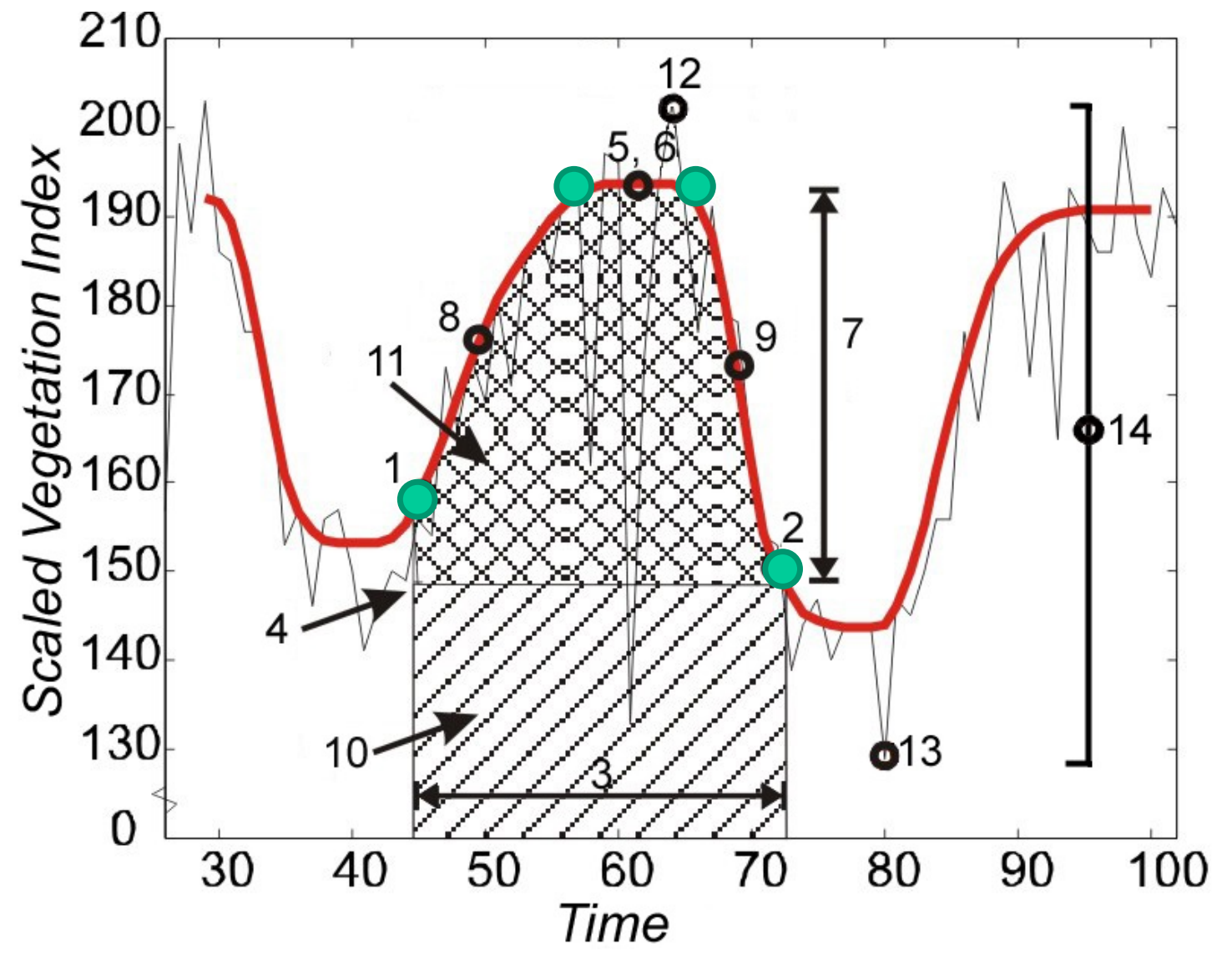

- Key phenology dates
2. End of season

3. Length of season

4. Base VI value

5. Peak time

6. Peak value

7. Amplitude

8. Left derivative

9. Right derivative

10. Integral over season absolute

11. Integral over season scaled

12. Maximum value

13. Minimum value

14. Mean value

15. RMSE

TIMESAT - a program for analyzing time-series of satellite sensor data Per Jonsson \& Lars Eklund, Computers \& Geosciences 30:833-845, 2004. 


\section{How to Determine the Key Phenology Dates}

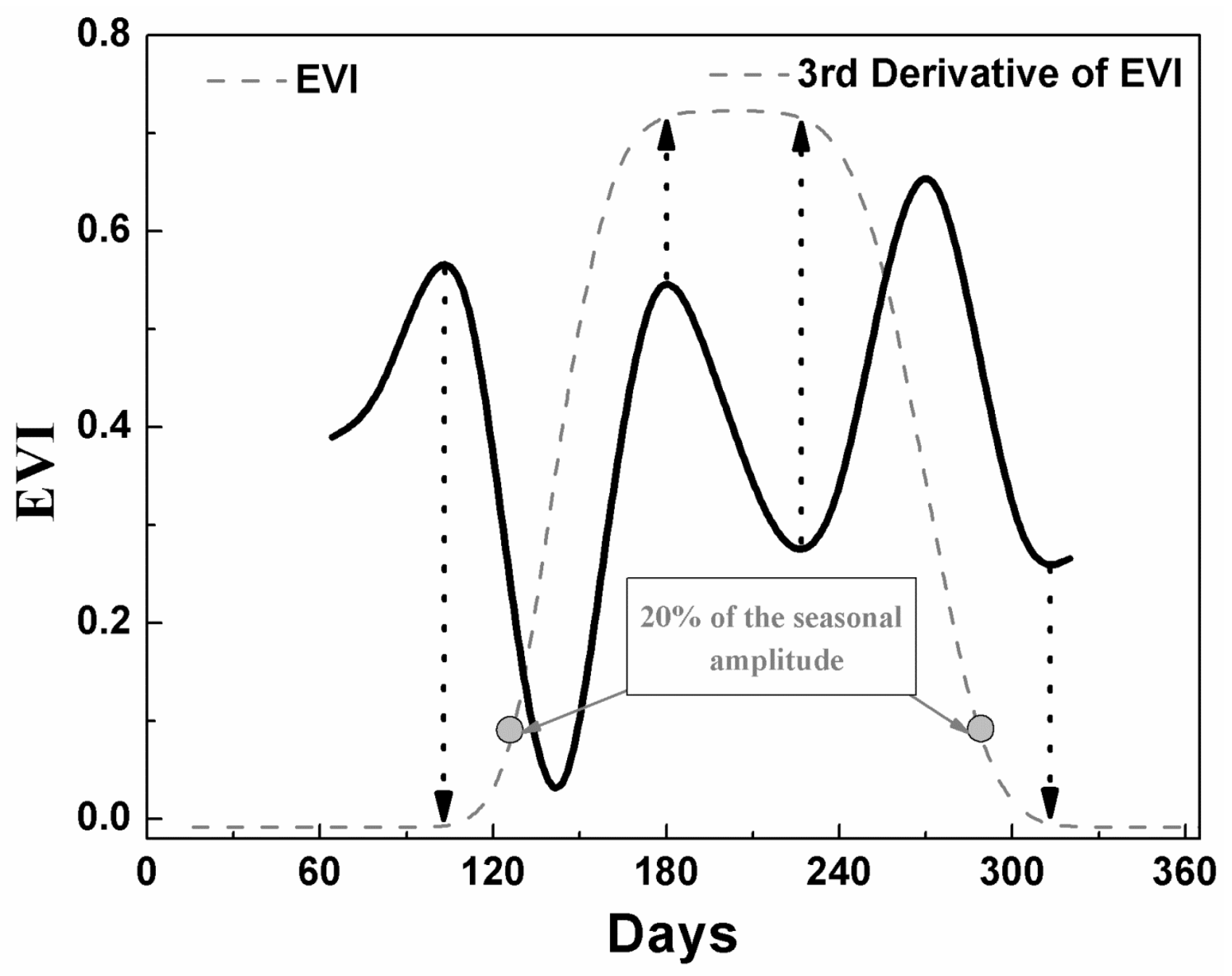




\section{Eliminate noise and fill data gap during the winter}

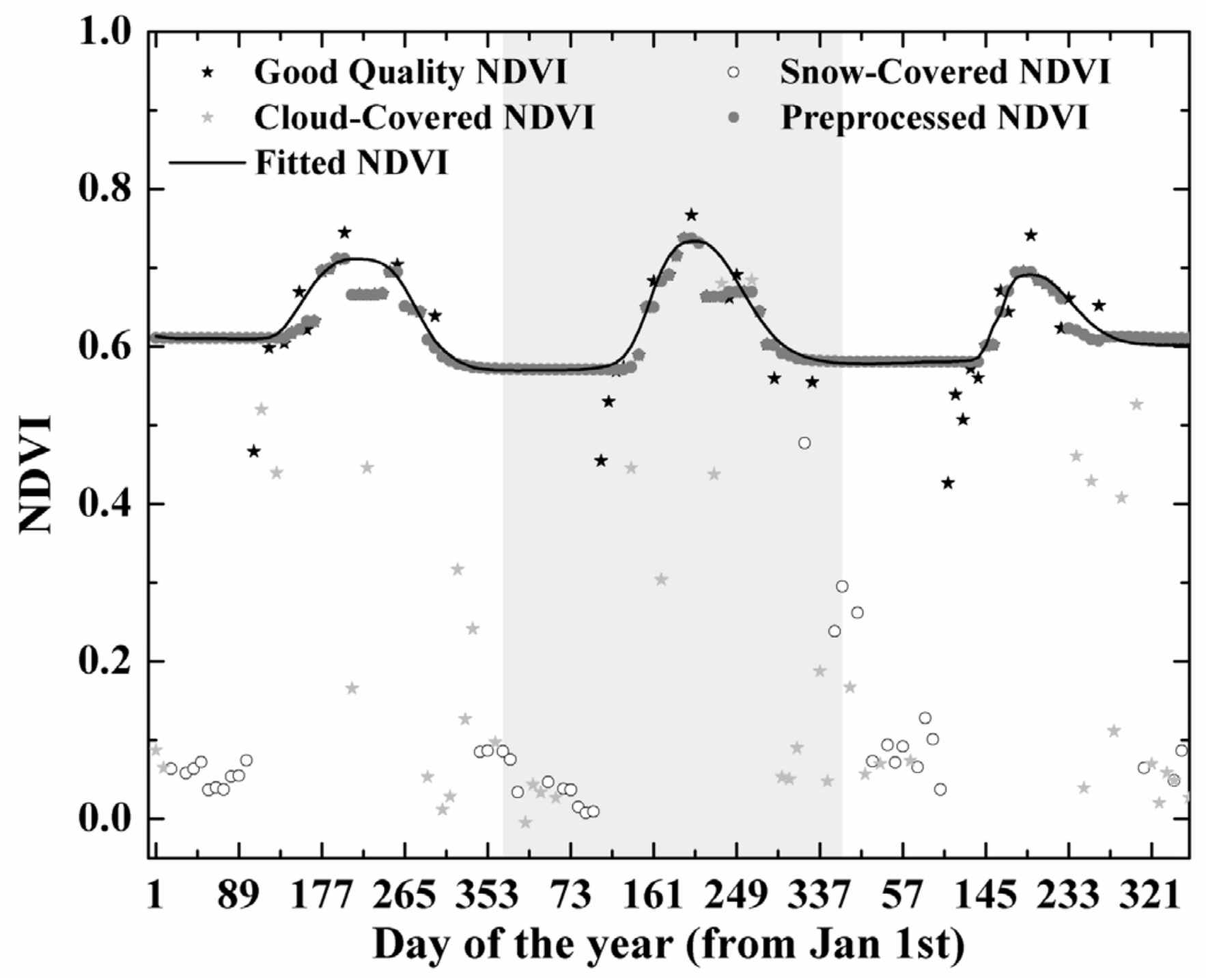




\section{Retrieve unevenly distributed growing seasons}

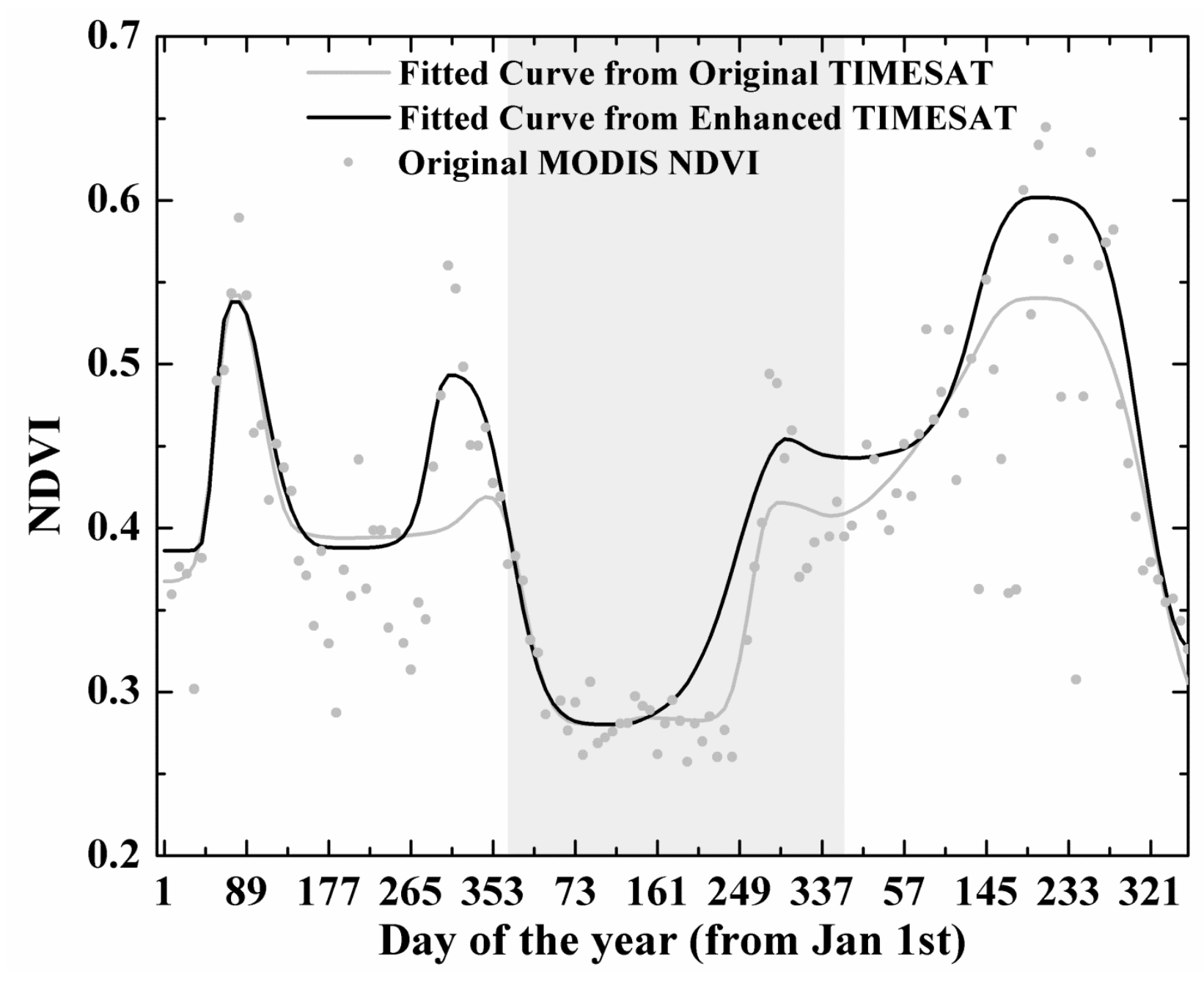




\section{moors \\ Phenology Dates NDVI vs. EVI (1)}

Greenup $_{\mathrm{NDVI}}$

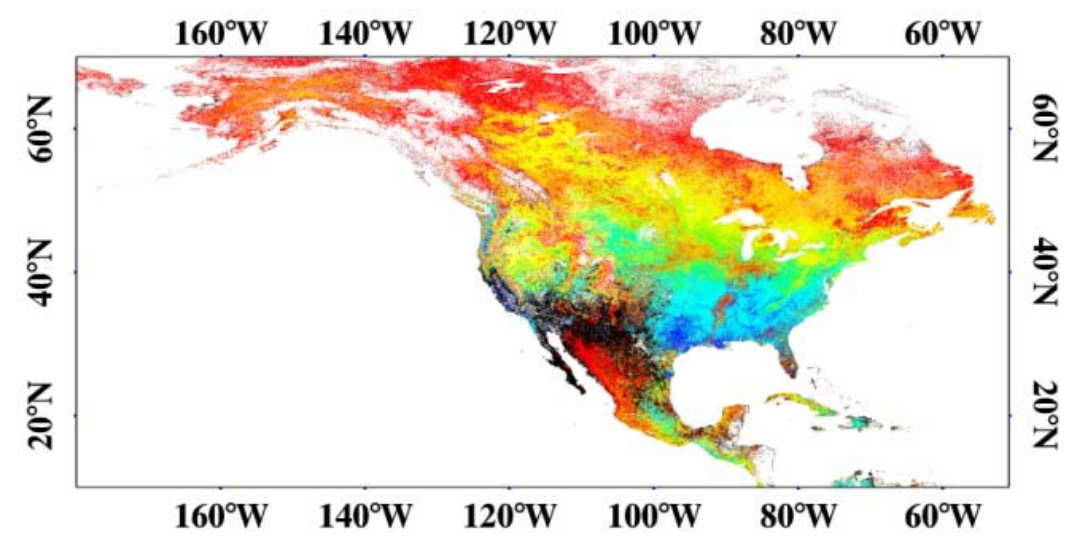

Greenup $_{\text {EVI }}$
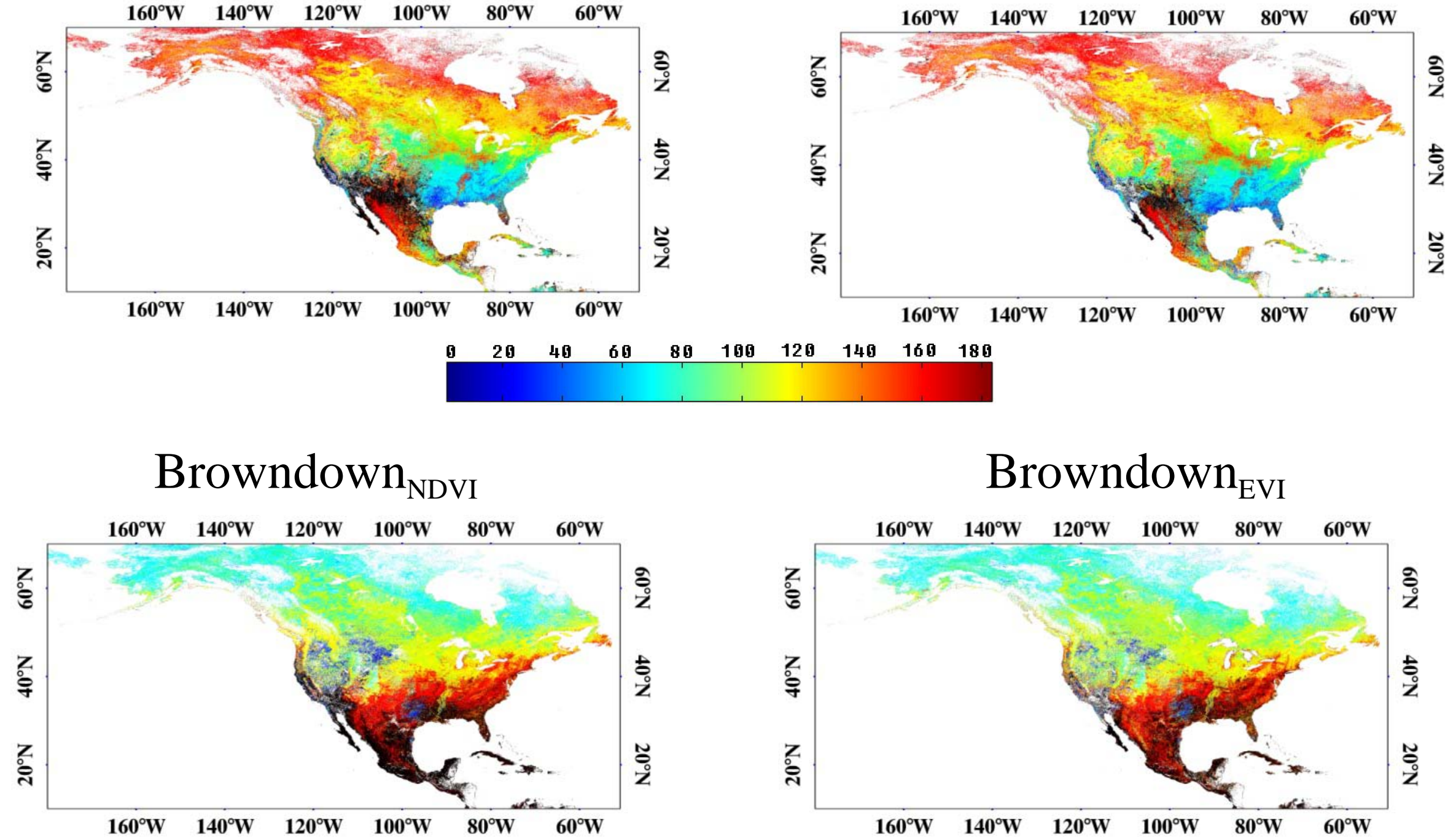


\section{Phenology Dates NDVI vs. EVI (2)}
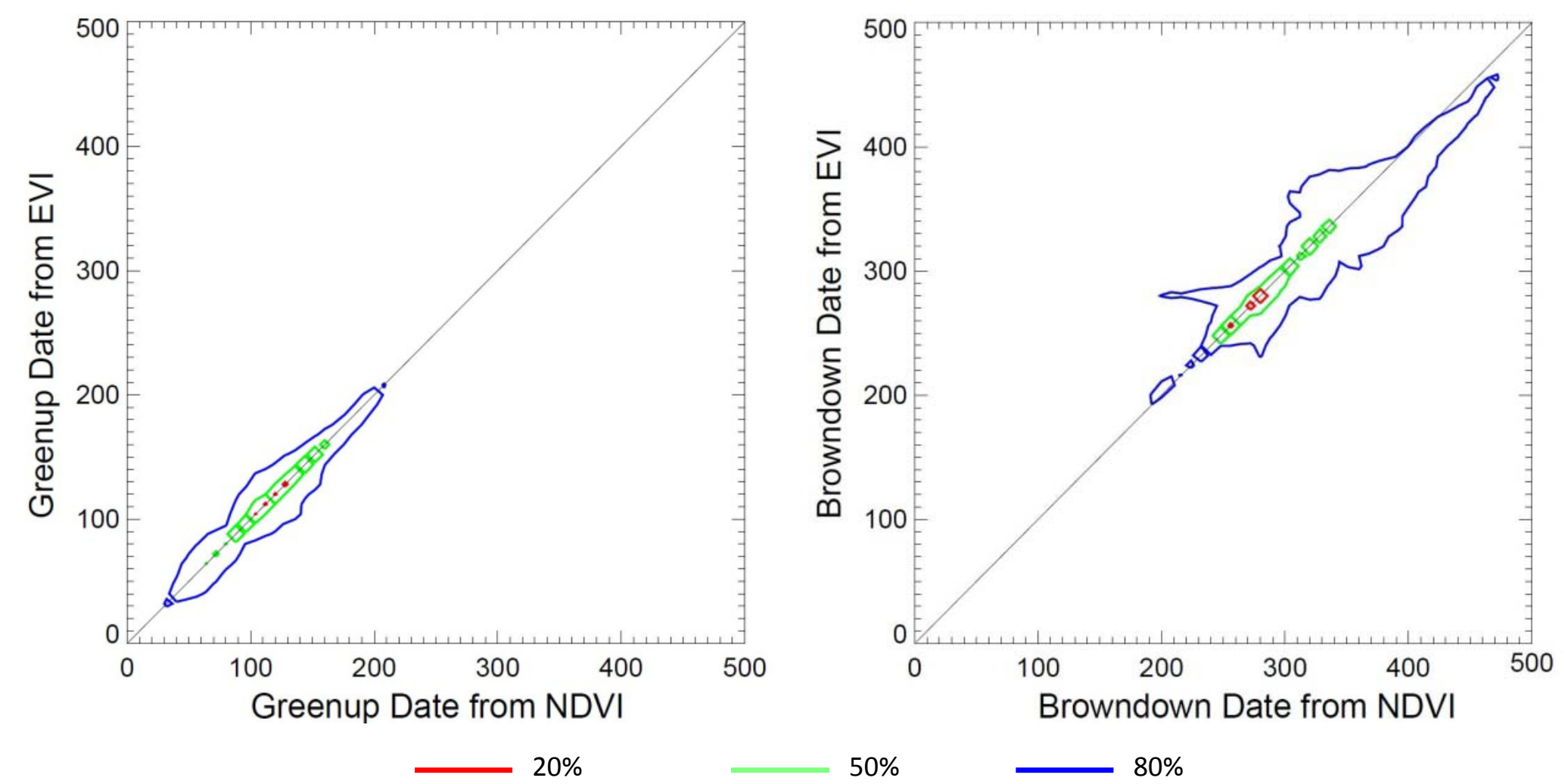

- More than $50 \%$ of the pixels have similarly retrieved greenup/browndown dates.

- More difference between browndown dates because the browndown is a more gradual progress than greenup, which makes greenup easier to determine. 
5/16

$8 / 28$

10/15

11/01

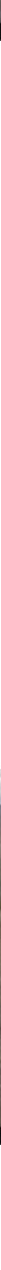




\section{Comparison with Field Record}

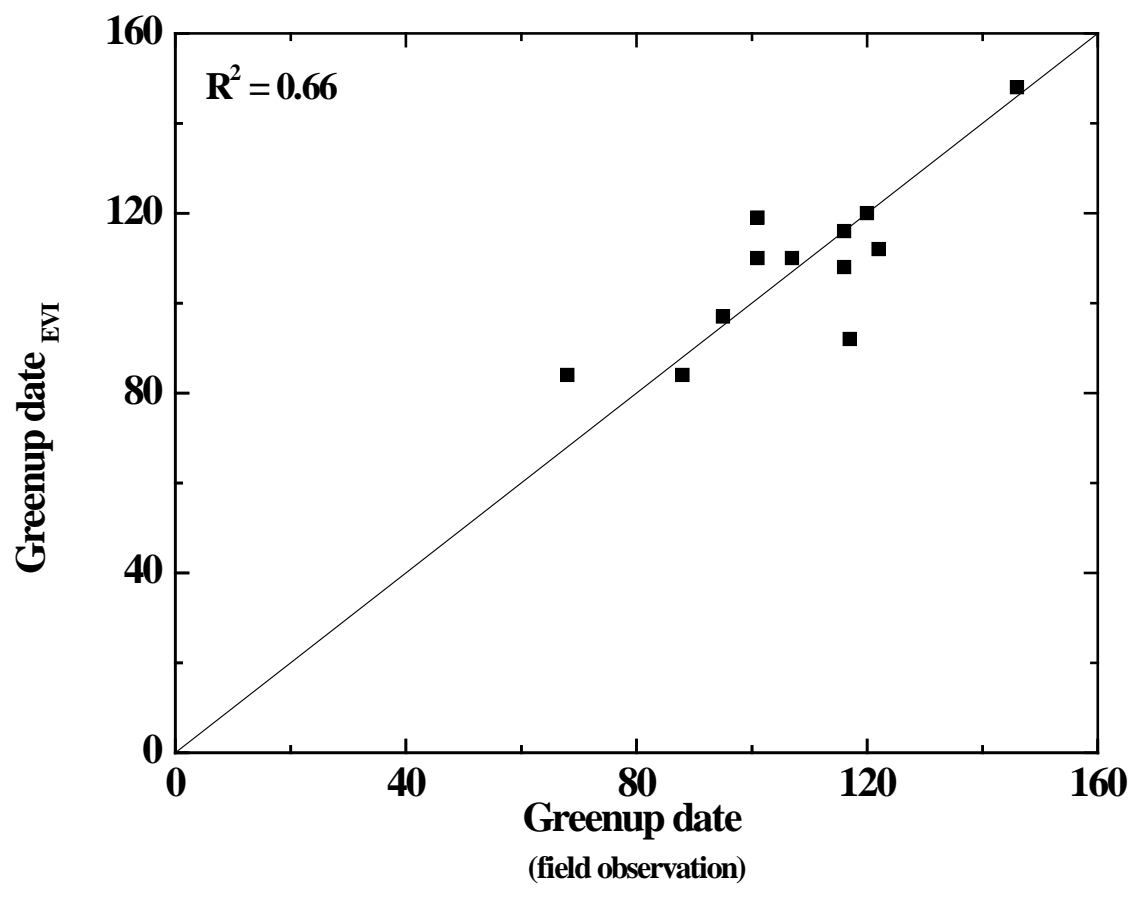

\begin{tabular}{|l|l|l|}
\hline Site/Network Name & Site Numbers & Observed Events \\
\hline Chequemegon Ecosystem Atmosphere Study & 2 & First Appearance of leaves \\
\hline GLOBE & 5 & First Appearance of leaves \\
\hline Harvard Forest LTER & 1 & First Appearance of leaves \\
\hline Howland Research Forest & 1 & First Appearance of leaves \\
\hline Long Lake Conservation Center & 1 & $\begin{array}{l}\text { First report of land surface temperature }> \\
60^{\circ} \mathrm{F}\end{array}$ \\
\hline Prairie Westlands Learning Center & 1 & $\begin{array}{l}\text { First report of Chorus Frogs and Trumpeter } \\
\text { Swans }\end{array}$ \\
\hline Rocky Mountain Biological Laboratory & & First Appearance of leaves \\
\hline
\end{tabular}




\section{Web-based data distribution system}

\section{http://accweb.nascom.nasa.gov/}

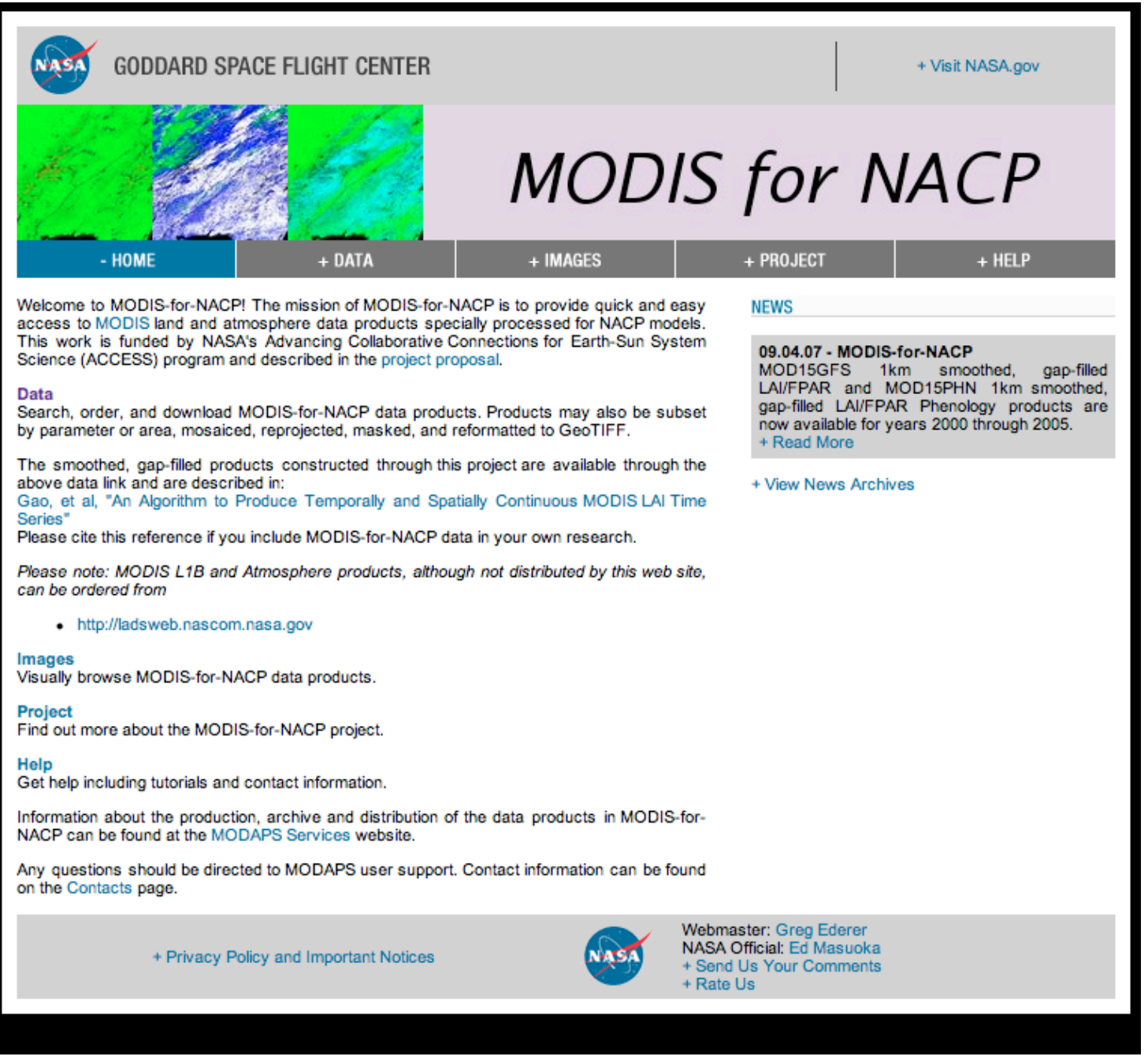

Offering original, smooth/gap-filled LAI, FPAR, EVI \& NDVI, and phenology metrics derived from $\mathrm{LAI} / \mathrm{EVI} / \mathrm{NDVI}$ products with the following data services:

- Subset by geographic area

- Subset by data layer

- Reproject

- Mosaic

- Aggregation

- Re-format (to GeoTIFF). 


\section{Application: Mapping nectar flow phenology with satellites and Honey Bee hives to assess climate impacts}

- $\sim 10^{5}$ Flowering plant species.

- $\sim 10^{4}$ Pollinating insect sp., many in decline.

- Dependencies, Areal Abundances, Trends, and Climate Response Functions of individuals or their partners are very poorly known.

- Our bees, ecosystems, and food depend on these interactions being successful.

- Little time for a species-by-species approach, we need to generalize in a

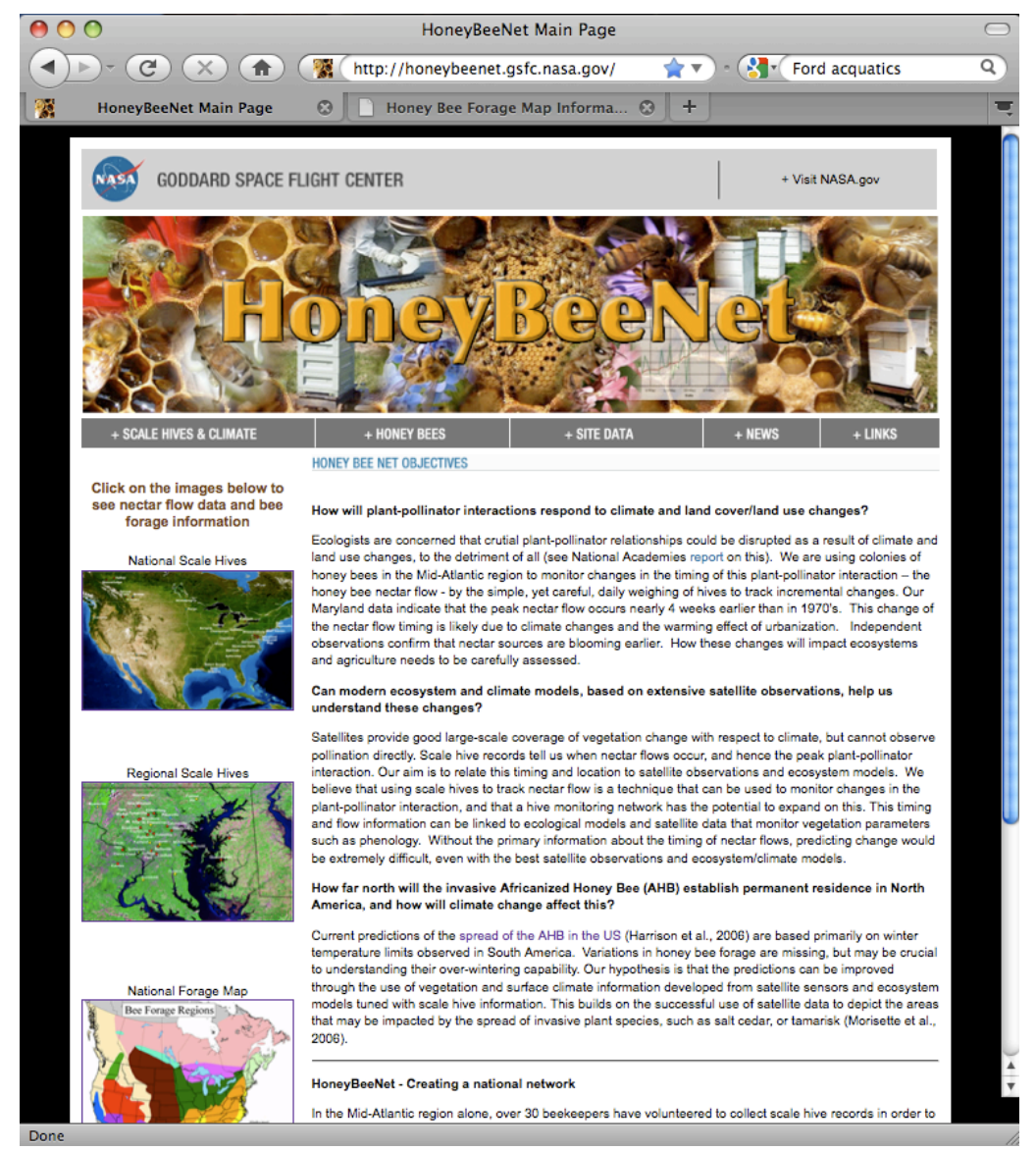
smart way. 


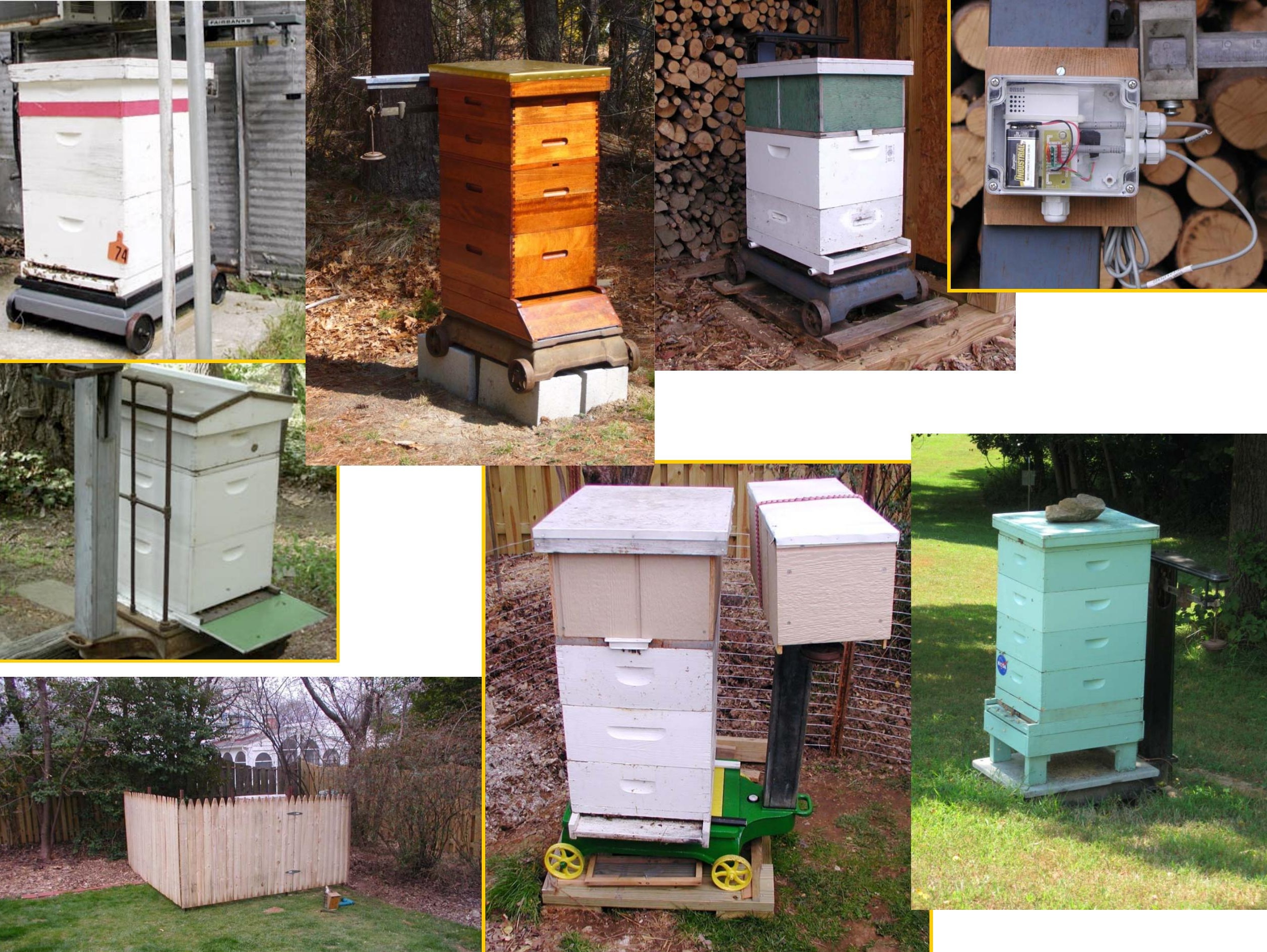




\section{Honey Bee Nectar Flow (HBNF) Metrics}

Highland 2006

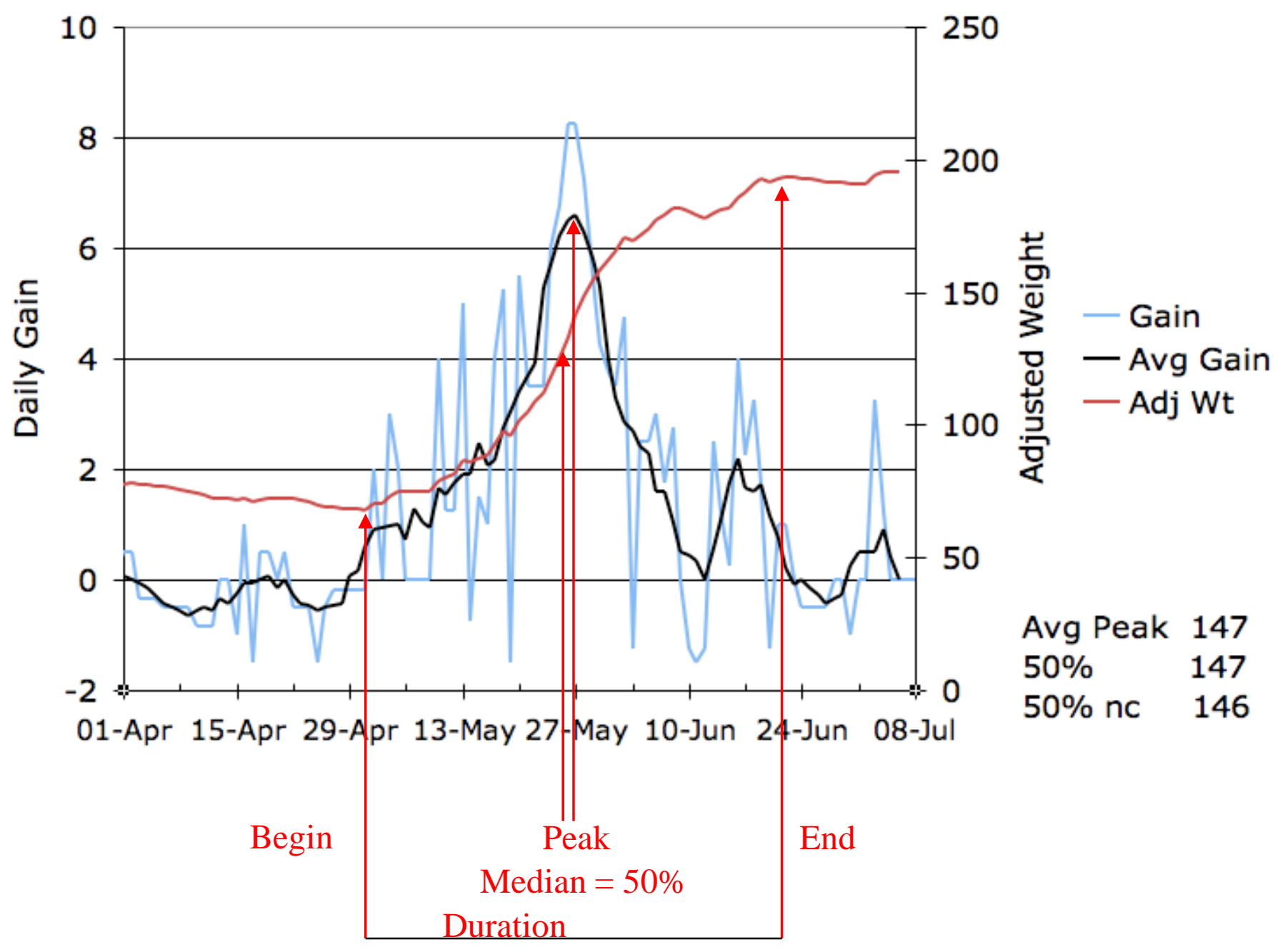

Composite integral covering 1000 hectares, of plants, pollinators, and environmental variables of successful interactions. 

Phenology product (1)

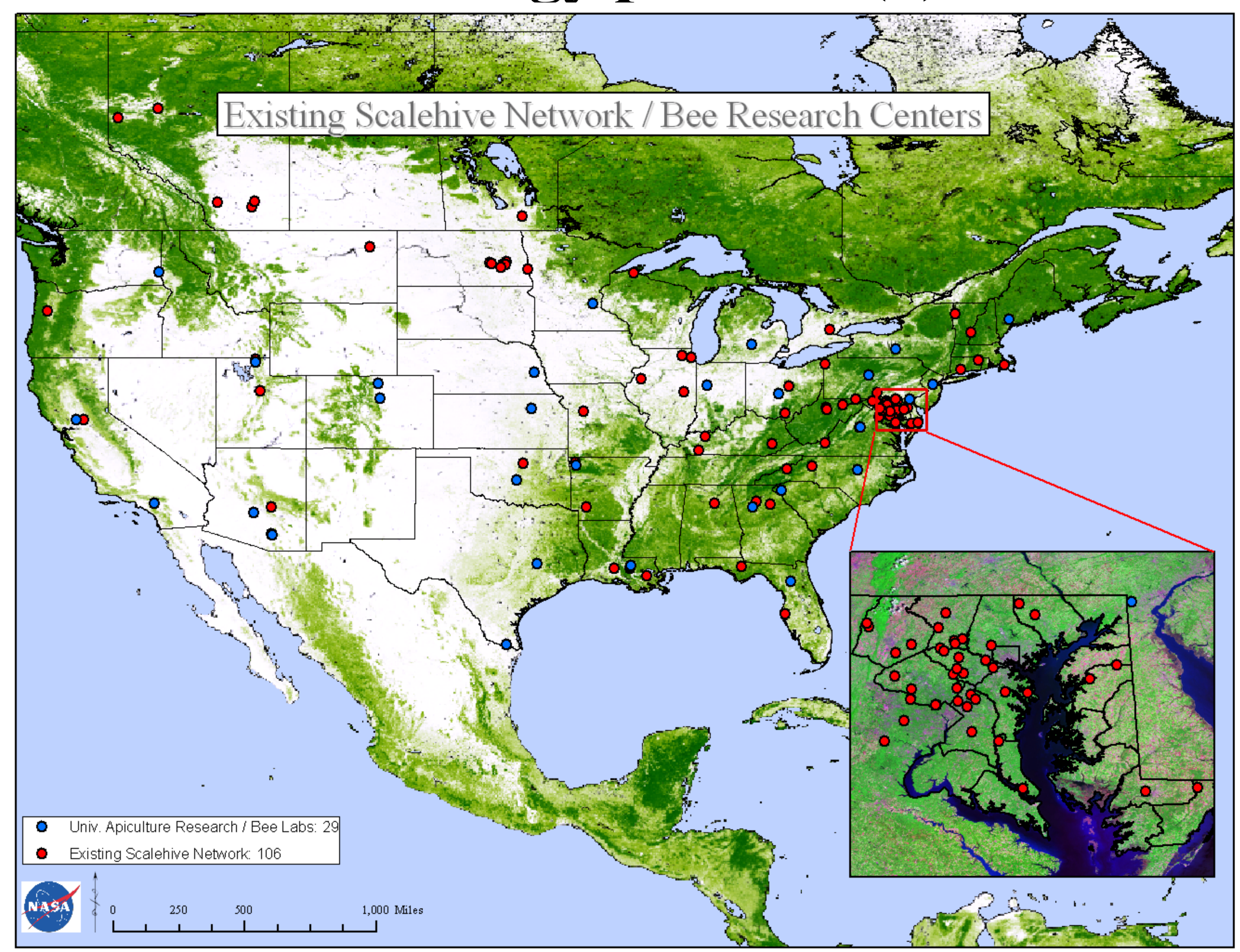




\section{Linking Scale Hive Observations MODIS Phenology product (2)}

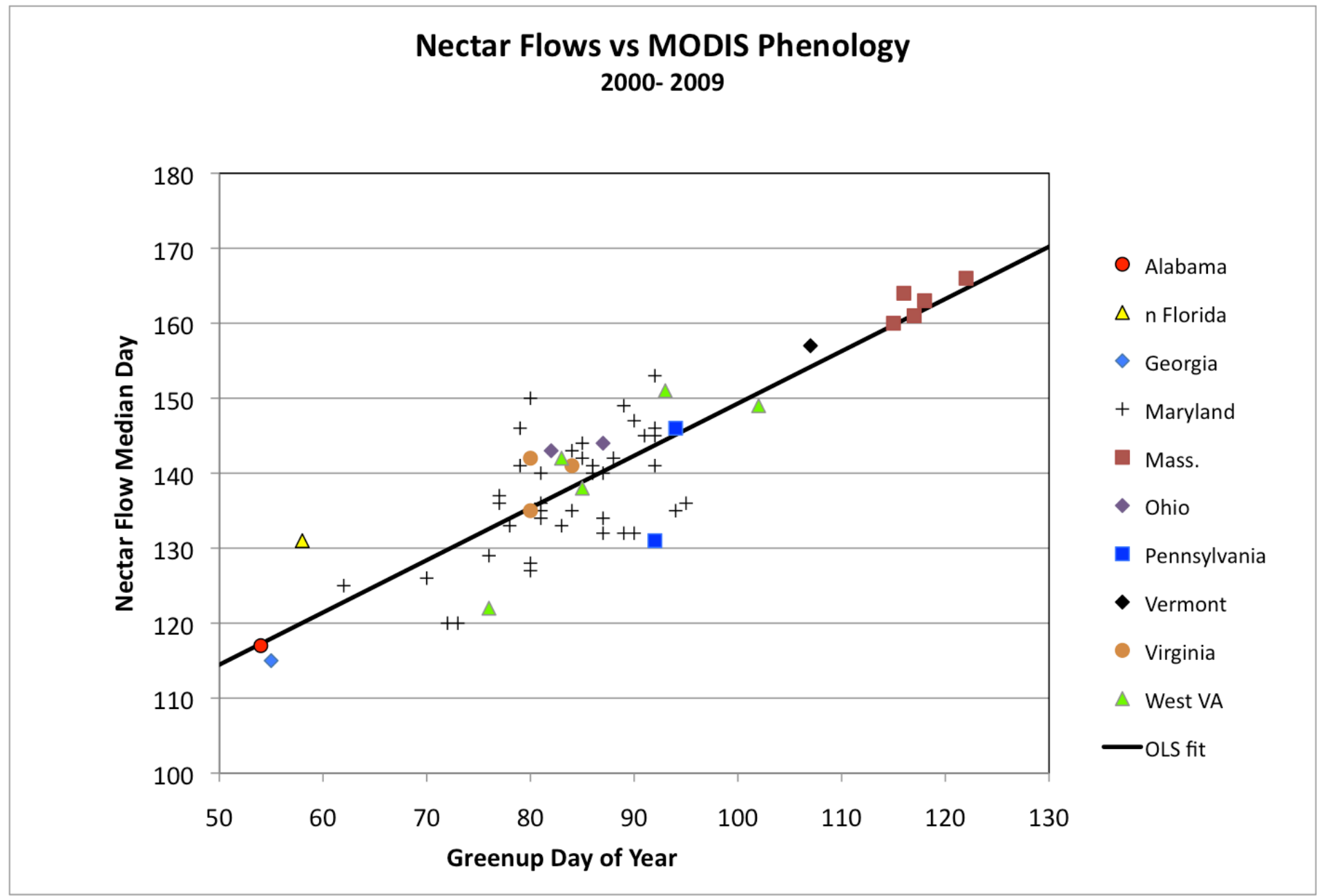

Spring, Median (50\% gain), Eastern US, edited with QC criteria. Louisiana, S. Florida excluded. For trees, shrubs, mixed cropland mosaic, urban land cover types. 


\section{moots \\ Retrieved 50\% nectar flow date}
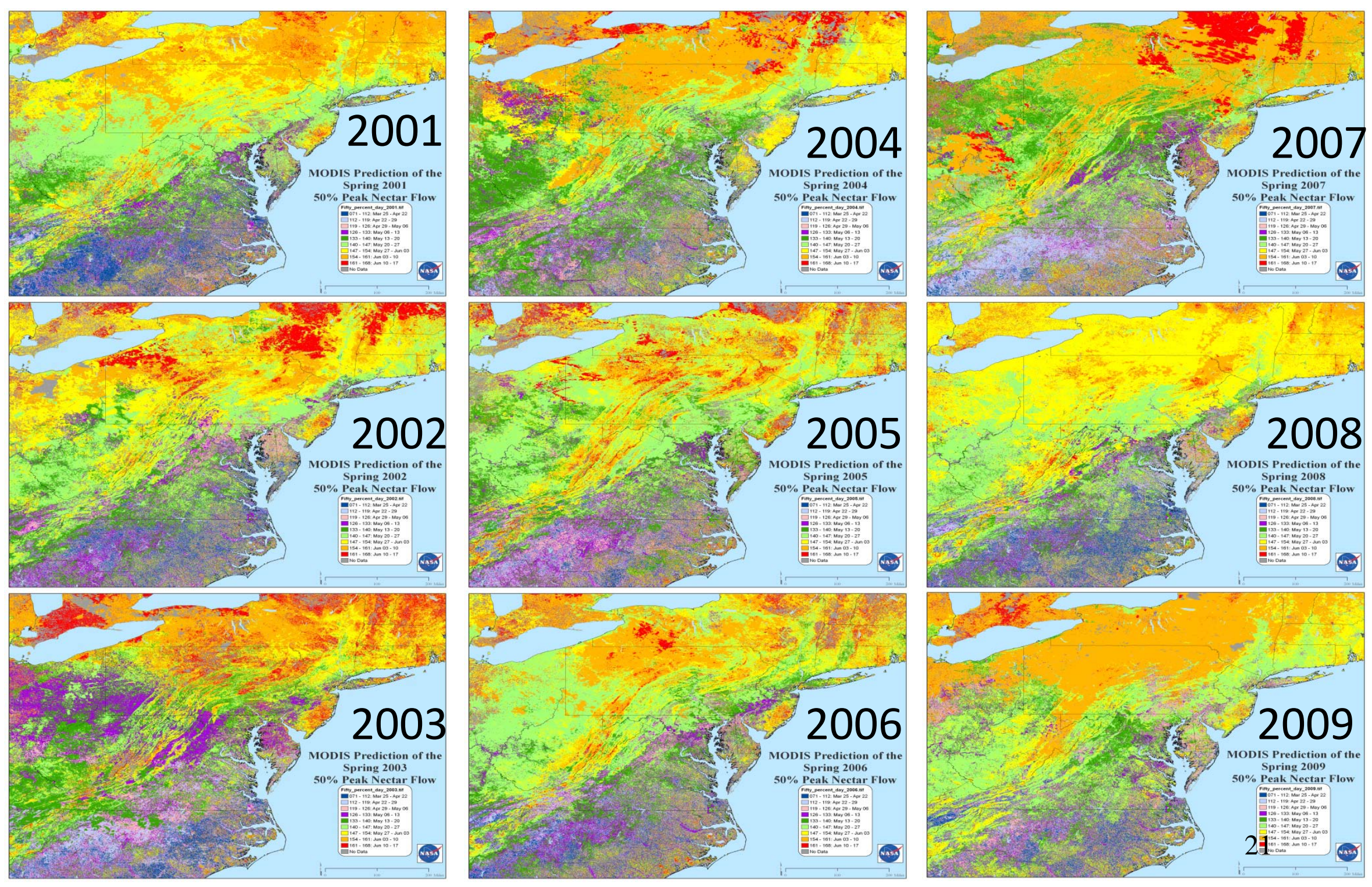


\section{Summary}

- Smoothed and gap-filled VI provides a good base for estimating vegetation phenology metrics.

- The TIMESAT software was improved by incorporating the ancillary information from MODIS products.

- A simple assessment of the association between retrieved greenup dates and ground observations indicates satisfactory result from improved TIMESAT software.

- One application example shows that mapping Nectar Flow Phenology is tractable on a continental scale using hive weight and satellite vegetation data.

- The phenology data product is supporting more researches in ecology, climate change fields. 


\section{Questions?

$$
\text { ? }
$$




\section{Smooth and Gap-fill algorithm}

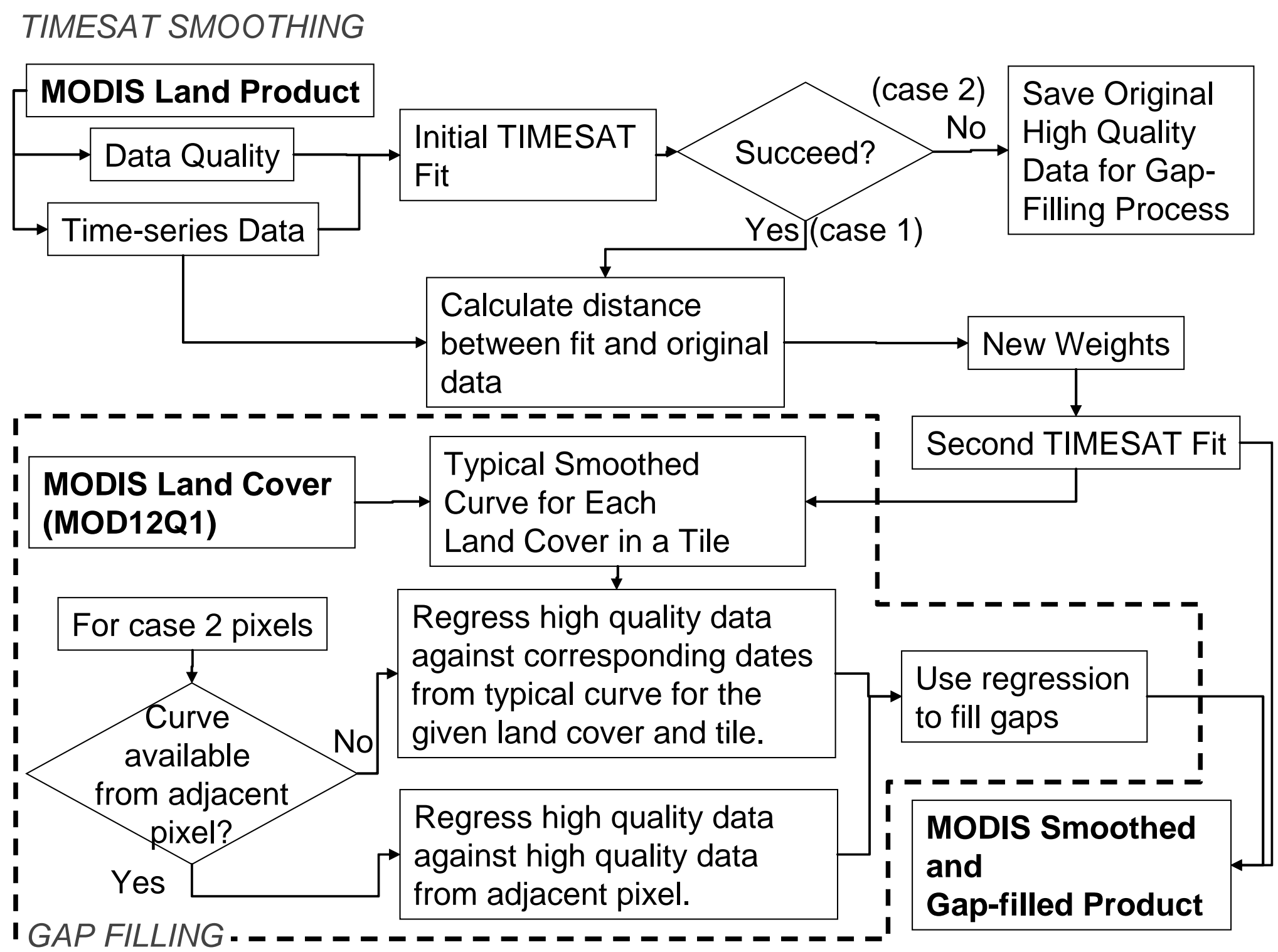




\section{Gap-fill Phenology Algorithm}

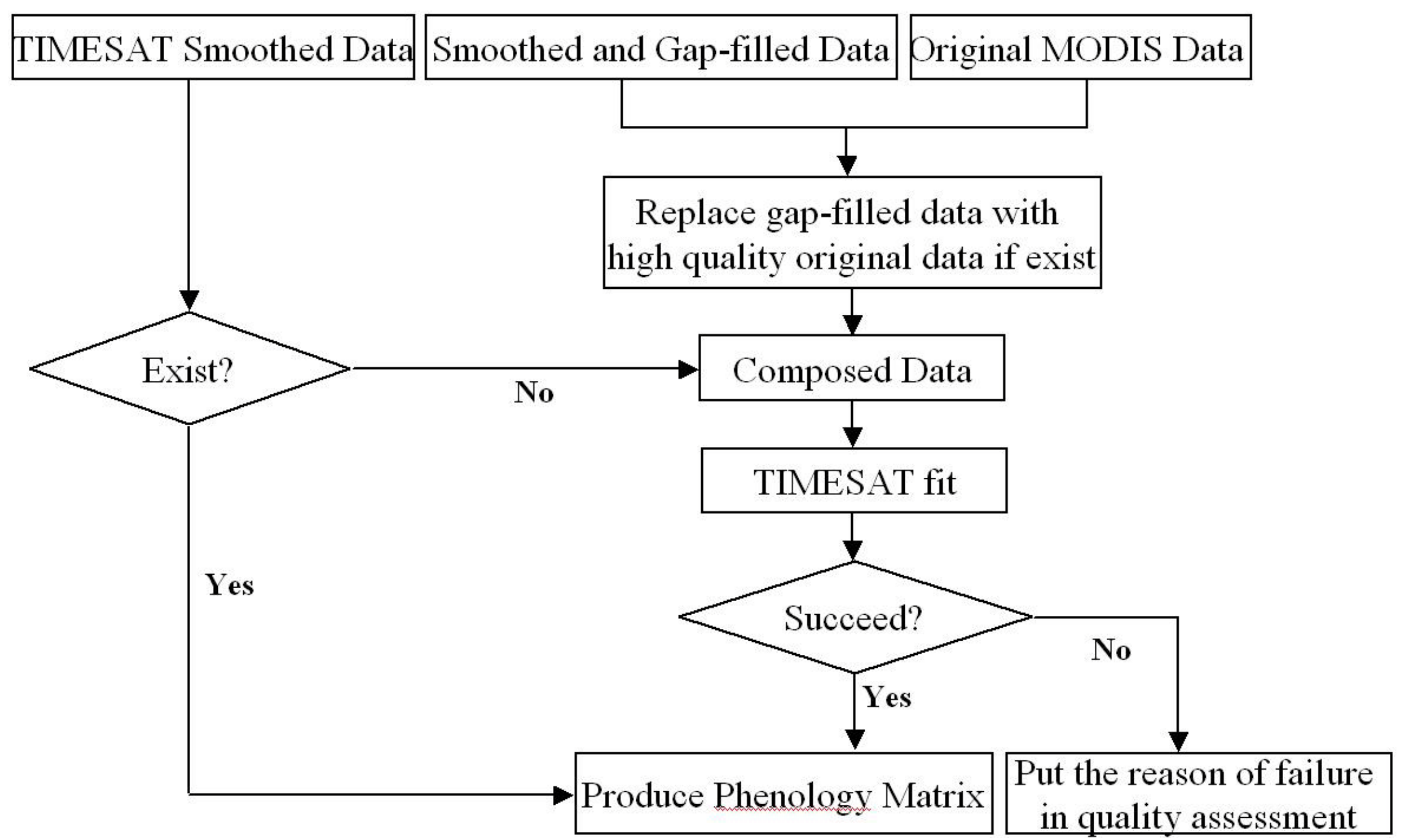

